\title{
The risk of legalizing marijuana as a recreational drug in North America
}

\section{Introduction}

The risk factors in legalizing marijuana as a recreational drug in North America are especially high as their impact leads to impairing mental health in early and continued users of recreational marijuana. Studies suggest that persistent marijuana possession, use, and distribution can precede and herald criminal and illicit activities; detention and incarceration then become possibilities. North America needs to revisit policies regarding legalizing marijuana for recreational use. The Canadian government is moving to dramatically change the laws governing marijuana use.

Justice Minister Jody Wilson-Raybould has announced that the Trudeau government is resolute to propagate legislation to decriminalize and normalize the recreational use of marijuana in Canada during the spring of 2017. The Liberal government is trying to make sense of the US policy on this matter taking into consideration the views of President Donald Trump. ${ }^{1}$

Justice Minister Wilson-Raybould has stated that the Liberal government is in the process of presenting a task force report on the issue at the end of last year. "Among more than 80 recommendations, the panel suggested Canadians 18 and older should be allowed to buy recreational cannabis through storefront and mail-order sales. The world is watching Canada as it moves to green light recreational pot because no other major western country, with the exception of Uruguay, has fully legalized the drug". ${ }^{1}$ In light of the above statement, there is a need for more consideration of the potential impact of legalizing marijuana for recreational use.

Discussions are underway with Public Safety Minister Ralph Goodale and with U.S. counterparts about any potential impacts of the Canadian government's plans. There are concerns that initiating marijuana legislation in Canada could produce complications with the U.S. government. ${ }^{1}$ In the following sections we will discuss the gateway theory, current data on adverse effects of marijuana use, and conclude with our thoughts on what the Canadian government should be doing.

\section{Gateway theory}

The gateway hypothesis ${ }^{2}$ deals with the sequencing, association, and causation questions. Sequencing refers to the usage of alcohol and cigarettes before the use of marijuana. The association aspect alludes to marijuana smoking being positively correlated with other illicit drugs at a later date. The causation feature explicates the notion that marijuana use induces pleasurable feelings that stimulate an urge to expend and consume more potent illicit substances and drug use. ${ }^{2}$

\section{Current data on adverse effects of marijuana}

Studies indicate that legalizing marijuana as a recreational drug will most likely result in deficits in self-control and increased disinhibited behavior. ${ }^{3,4}$ Psychosocial risk factors are associated with consequences such as heavy alcohol use, enhanced sexual behaviours, and dangerous driving behaviours.
Volume 3 Issue 4 - 2017

\author{
Edith Samuel \\ Crandall University, Canada
}

Correspondence: Edith Samuel, Associate Professor of Psychology, Crandall University, 36 Chateau Drive Moncton NB, Canada, EIG 5N7, Tel 506204 5922, Email edith749l@hotmail.com

Received: March 31, 2017| Published: May 18, 2017

Research has further validated the premise that chronic marijuana use during adolescence results in mental health problems in later adulthood. ${ }^{5}$ Physiological symptoms emerge in young men such as metabolic, cardiac and respiratory setbacks as well as psychological problems namely psychosis, anxiety, and depression. ${ }^{6}$ Since marijuana is the third most regularly used drug in North America, it is necessary that users are informed about the prospects of later depressive and anxiety issues that may emerge with continued use.

There have been associations of recreational marijuana use with PTSD and trauma in a sample of participants. ${ }^{7}$ This study focused on a sample of 34,396 participants who had a life-time of cannabis use, and were trauma-exposed cannabis users. Individuals distressed with cannabis use disorders, abuse and dependence are at risk of developing major anxiety disorders, generalized anxiety disorders, panic disorders, social anxiety disorders, personality disorders, major depression, and possibly alcohol dependence. ${ }^{7}$

Adolescents and youth in Norway are prone to coming into contact with the law as a result of continued cannabis use. ${ }^{8}$ Such a scenario poses to be a concerning trend. Immigrant groups associated with cannabis growing are related to illicit activities and crime. ${ }^{9}$

\section{Conclusion}

The risk factors, therefore, are especially high as they lead to exacerbating and worsening mental health problems in early and continued users of recreational marijuana. As well, continued marijuana possession, use, and distribution can precede and herald criminal and illicit activities with detention and incarceration becoming a reality. Taking into account the above studies, it is imperative that Canada along with the US revisit their policies on legalizing marijuana for recreational use.

\section{Acknowledgements}

None.

\section{Conflict of interest}

The author declares no conflict of interest. 


\section{References}

1. Canada: The Canadian Press; 2017.

2. Denise B Kandel. Stages and Pathways of Drug Involvement: Examining the Gateway Hypothesis. USA: Cambridge University Press; 2002:5-13.

3. Vogel Sprott M, Fillmore Mark T. Expectancy and behavioural effects of socially used drugs. In: Kirsch Irving, Editor. How expectancies shape experience. Washington: American Psychological Association; 1999. p. $215-232$.

4. Linden Carmichael AN, Lau Barraco C. A preliminary investigation of caffeinated alcohol use during Spring Break. Subst Use Misuse. 2016;51(7):937-941.

5. Bechtold J, Simpson T, White HR, et al. Chronic adolescent marijuana use as a risk factor for physical and mental health problems in young adult men. Psychol Addict Behav. 2015;29(3):552-563.
6. Grunberg VA, Cordova KA, Bidwell LC, et al. Can marijuana make it better? Prospective effects of marijuana and temperament on risk for anxiety and depression. Psychol Addict Behav. 2015;29(3):590-602.

7. Kevorkian S, Bonn Miller MO, Belendiuk K, et al. Associations among trauma, posttraumatic stress disorder, cannabis use, and cannabis use disorder in a nationally representative epidemiologic sample. Psychol Addict Behav. 2015;29(3):633-638.

8. Schoenmakers YMM, Bremmers BO, Kleemans ER. Strategic versus emergent crime groups: the case of Vietnamese cannabis cultivation in the Netherlands. Global Crime. 2013;14(4):321-340.

9. Pedersen W, Skardhamar T. Cannabis and crime: findings from a longitudinal study. Addiction. 2009;105(1):109-118. 